\title{
Arresting pulmonary atresia intact ventricular septum...only if you have to
}

\author{
Harold M. Burkhart, MD, Jess L. Thompson, MD, and Ron E. Angona, CCP
}

\footnotetext{
From the Division of Cardiovascular and Thoracic Surgery, University of Oklahoma Health Sciences Center, Oklahoma City, Okla.

Disclosures: Authors have nothing to disclose with regard to commercial support.

Received for publication May 8, 2017; accepted for publication May 8, 2017; available ahead of print June 2 , 2017.

Address for reprints: Harold M. Burkhart, MD, Division of Cardiovascular and Thoracic Surgery, University of Oklahoma Health Sciences Center, PO Box 26901, WP-2230, Oklahoma City, OK 73105 (E-mail: Harold-burkhart@ouhsc.edu).

J Thorac Cardiovasc Surg 2017; 154:e67

$0022-5223 / \$ 36.00$

Copyright (c) 2017 by The American Association for Thoracic Surgery

http://dx.doi.org/10.1016/j.jtcvs.2017.05.040
}

Pulmonary atresia intact ventricular septum (PA-IVS) is a rare congenital cardiac anomaly composed of varying degrees of right ventricle (RV) and tricuspid valve hypoplasia. Perhaps most important, there are a wide range of coronary artery anomalies, including RV to coronary artery fistulas, coronary artery stenosis, and coronary artery atresia. RV to coronary artery fistulas are common, occurring in up to $75 \%$ of patients in some series. ${ }^{1,2}$ Coronary artery atresia, interruption, or severe stenosis may result in an RVdependent coronary circulation (RVDCC) in which right and left myocardium are reliant on blood flow via fistulas from the RV. This coronary anatomy is rare, occurring in approximately $5 \%$ to $10 \%$ of patients. ${ }^{3}$ The literature is clear that patients with RVDCC have a poor prognosis, and consideration for primary transplantation should be given.

In this issue of the Journal, Dr Woods ${ }^{4}$ presents a highrisk patient with PA-IVS and RVDCC who was listed for cardiac transplantation after successful resuscitation from cardiac arrest while undergoing coronary angiography. Without a suitable donor and evidence of clinical deterioration, the infant was taken to the operating room for a successful atrial septectomy and bidirectional cavopulmonary shunt with pulmonary artery patch reconstruction. This report is important in that it offers an alternate technique description for successful cardioplegia administration in a patient with RVDCC. By simultaneously administering cardioplegia into the aorta and RV by way of the tricuspid valve, good coronary perfusion and cardiac arrest are obtained. It is reasonable to conclude that this method ensured cardioplegia penetrance into the postatretic or stenotic coronary regions that would have gone unprotected with simple antegrade administration.

Although this case report provides a potentially useful technique when faced with inducing arrest in a patient with PA-IVS and RVDCC, it should be remembered that typically we strive to avoid cardioplegic arrest in these patients. Catheter-based atrial septostomy may allow for staged palliation without cardioplegic arrest. While the

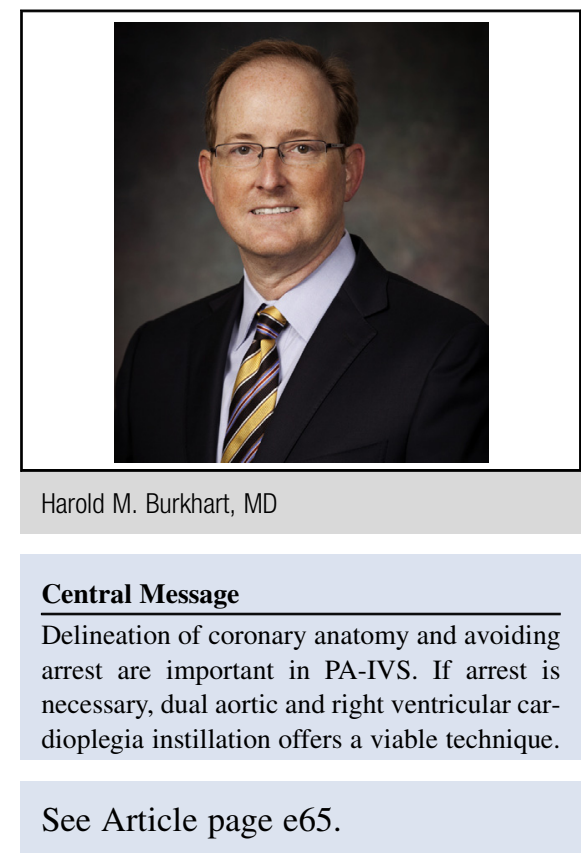

patient is on bypass, keeping the RV full ensures adequate coronary perfusion. If arrest is required, one must remember coronary anatomy is highly inconsistent, and simple antegrade cardioplegia administration may result in inadequate myocardial protection. Other useful maneuvers include cooling on bypass and topical cooling of the heart with ice. Regardless of these techniques, an arrested heart with RVDCC may still struggle to regain the RV systolic pressure wave required to support coronary perfusion coming out of an arrested state.

Coronary anatomy in PA-IVS is highly variable, and it is critical that the anatomy is defined. In general, especially with the high-risk patients with RVDCC, cardioplegic arrest should be avoided if at all possible. If arrest is necessary, dual aortic and right ventricular cardioplegia instillation offers a viable technique.

\section{References}

1. Cheung EW, Richmond ME, Turner ME, Bacha EA, Torres AJ. Pulmonary atresia/ intact ventricular septum: influence of coronary anatomy on single-ventricle outcome. Ann Thorac Surg. 2014;98:1371-7.

2. Louise Calder A, Peebles C, Occleshaw C. The prevalence of coronary arterial ab normalities in pulmonary atresia with intact ventricular septum and their influence on surgical results. Cardiol Young. 2007;17:387-96.

3. Guleserian KJ, Armsby LB, Thiagarajan RR, del Nido PJ, Mayer JE. Natural history of pulmonary atresia intact ventricular septum and right-ventricle-dependent coronary circulation managed by the single-ventricle approach. Ann Thorac Surg. 2006;81:2250-8.

4. Woods RK. Technique for myocardial protection in pulmonary atresia intact ventricular septum. J Thorac Cardiovasc Surg. 2017:154:e65-6. 